\title{
Enhancement of actuation ability of ionic-type conducting polymer actuators using metal ion implantation
}

\author{
Gursel Alici a ${ }^{a, b, *}$, Andres Punning ${ }^{c}$, Herbert R. Shea $^{c}$ \\ a University of Wollongong, School of Mechanical, Materials and Mechatronic Engineering, NSW, Australia \\ ${ }^{\mathrm{b}}$ ARC Centre of Excellence for Electromaterials Science University of Wollongong, Intelligent Polymer Research Institute Innovation Campus, NSW, Australia \\ c Ecole Polytechnique Fédérale de Lausanne (EPFL), Microsystems for Space Technologies Laboratory, Neuchâtel, Switzerland
}

\section{A R T I C L E I N F O}

\section{Article history:}

Received 14 December 2010

Received in revised form 12 February 2011

Accepted 13 March 2011

Available online 21 March 2011

\section{Keywords:}

Electroactive polymer actuators

Metal ion-implantation

Electrode conductivity

Actuator performance enhancement

\begin{abstract}
A B S T R A C T
In this study, we present the results and implications of an experimental study into the effect of gold-ion implantation on the actuation performance of ionic-type conducting polymer actuators, represented here by cantilevered tri-layer polypyrrole (PPy) actuators. We implant gold ions beneath the outer surfaces of PPy-based conducting polymer layers of the actuators in order to increase the conductivity of these layers, and therefore improve the overall conductivity of the actuators. A Filtered Vacuum Cathode Arc (FVCA) ion source was used to implant gold particles into the conducting polymer layers. Electrode resistance and capacitance, surface resistance, current response, mechanical work output of the actuator samples were measured and/or calculated for the actuator samples with and without gold implantation in order to demonstrate the effect of the gold-implantation. The current passing through the conducting polymer electrodes during their 'electrochemomechanical' actuation was measured to determine the charging time constant of the actuators. The mechanical displacement output of the actuators was recorded. The results demonstrate that the conductivity of the actuators increases noticeably, which has a flow on effect on the current response (i.e., charge injected into the polymer layers) and the mechanical work output. While the gold implanted actuators had a higher mechanical stiffness therefore a smaller displacement output, their time constant is smaller, indicating a higher response speed. The gold-implanted actuators generated a $15 \%$ higher mechanical work output despite the adverse effects on the polymer of the vacuum processing needed for the ion implantation.
\end{abstract}

(C) 2011 Elsevier B.V. All rights reserved.

\section{Introduction}

Electroactive polymers actuators are commonly referred to as artificial muscles [1] in view of their remarkable muscle-like properties: high flexibility, high strain and high energy density. Unlike other ionic-type conducting polymer actuators which can only operate in a liquid electrolyte, the ionic-type conducting polymer actuators considered in this study can operate in air and liquids using a very low electrical power $(1 \mathrm{~V}, 15-20 \mathrm{~mA})$ with a high speed ( $\sim 400 \mathrm{~Hz}$, depending on their size). When they are miniaturized further to micro-scale, becoming MEMS and bioMEMS devices, they can be suitable to applications ranging from biotechnology to micro-robots, especially in the field of life sciences.

Ionic-type conducting polymer actuators consist of at least one conductive polymer layer and an electrolyte reservoir, discussed in

\footnotetext{
* Corresponding author at: University of Wollongong, School of Mechanical, Materials and Mechatronic Engineering, NSW 2522, Australia. Tel.: +61 242214145; fax: +61 242215474 .

E-mail address: gursel@uow.edu.au (G. Alici).
}

more detail in Section 2. Fig. 1 is an example of tri-layer structure consisting of polymer-electrolyte-containing substrate-polymer. When an electrical potential is applied between the polymers on both sides of the actuator, an electrochemical reaction occurs; the polymer layers are electrochemically charged (doped) and discharged (undoped) through the exchange of charge-balancing ions between the polymer layers and the electrolyte stored in a passive substrate, in our case polyvinylidene fluoride (PVDF). This electrochemical reaction causes a volume change in the polymer layers, leading to swelling and contraction. The volume change is easily controlled by the electrical potential. The rate and magnitude of the flow of charges in or out of the polymer layers depends on: the electrical conductivity of electroactive polymer layers, the ionic conductivity of the electrolyte, the diffusion time of ions in the polymer layers, the porosity and geometry of the polymer layers, and applied potential difference. The fundamental (or charging) time constant of these actuators depends on their total resistance and capacitance (RC). The lower the total resistance, the faster the actuation process. Further, it is known that there is a direct relation between the charging rate and the actuation strain or mechanical displacement generated [7]. 


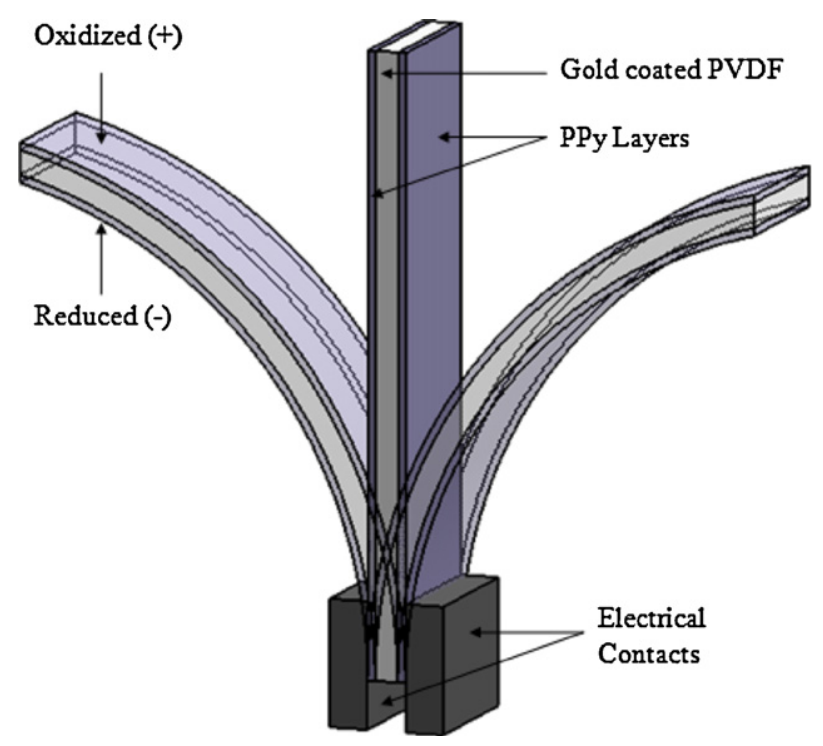

Fig. 1. Structure and schematic representation of the operation principle of the cantilevered polymer actuators.

With this in mind, it is the aim of this study to increase the electrical conductivity of the electroactive polymer layers by implanting gold ions a few tens of $\mathrm{nm}$ beneath the outer surface of the polymer layers, which are electrically contacted by a pair of metal electrodes covering a small fraction of the polymer (see Fig. 1). As widely reported in the literature [3-15], if the conductivity of the contacts and the polymer is very good, there will be a small ohmic potential drop along the actuator length, and the charging rate will be high, which generate higher strains. The higher is the strain, the higher is the tip displacement of the actuators. The function of these additional layer of gold is to increase the conductivity of the polymer electrodes, and thus to also minimize the ohmic (IR) potential drop along the actuator length.

As reported recently [16], the $\mathrm{Cl}_{2}$ and $\mathrm{SF}_{6}$ plasma treatment of the ionic-polymer metallic composite (IPMC) actuators has improved the actuation performance of this class of actuator including operational life, bending displacement, and blocking force. This improvement is due to an increase in the surface conductivity. The higher is the conductivity of the surface, the higher is the bending displacement of the actuators. IPMC consist of an ionic polymer sandwiched between two compliant electrodes. The ionic polymer (cell separator) Nafion is plasma coated in order to increase the penetration of the platinum particles in order to create an electrode coating into the Nafion layer. With the platinum nanoparticles with a thickness of $50-70 \mathrm{~nm}$, the surface conductivity and capacitance of the IPMC actuators are increased by 20 times and 2 times, respectively, compared to an actuator sample without any plasma treatment. In another relevant study, Punning et al. [17] reported on their experimental study on the surface resistance of IPMC actuators and sensors. They conclude that (i) the surface resistance changes with the radius of curvature of the actuators and (ii) there is a discernable difference between the resistance of the compressing surface and expanding surface of the cantilevered IPMC actuators. Because the IPMC actuators have two metallic electrodes through which they are electrically actuated, there is a wide literature on improving the electrical characteristics of the metallic electrodes and their implications for the actuation performance [16-19]. But, the actuators considered in this study have nonmetallic, but inherently conducting polymers as electrodes whose conductivity has a significant effect on their actuation performance. Therefore, improving the conductivity of these electrodes through a permanent layer of a conductor such as implanted gold particles is a significant research problem. Previous attempts to deposit a conducting metallic layer on the surface of conducting polymers films (which were used as linear actuators in an aqueous electrolyte) were not successful due to the poor binding (no interpenetration between the gold and the polymer layers) between the polymer surface and the thin film coatings [20-22] or excessive stiffening.

In this study, we employ a low-energy ( $5 \mathrm{keV}$ ) metal ion implantation technique based on a pulsed vacuum arc plasma source to increase the conductivity of the polymer electrodes, and therefore enhance the actuation of performance of this class of electroactive polymer actuators. This ion-implantation technique has been employed before to make compliant gold electrodes in dielectric elastomer actuators [2,27] and stretchable electrodes [25] by creating a $20 \mathrm{~nm}$ thick gold-silicon nanocomposite $[6,26]$. For the first time, we employ this technique to increase the conductivity of the ionic-type conducting polymer actuators, hence to enhance their actuation ability, which depends on the polymer conductivity. We compare the experimental and numerical results from bare actuator samples and from gold-implanted samples to demonstrate the efficacy of the gold implantation in increasing their performance. Electrode resistance, electrode capacitance, surface resistance, current response, time constant, electrical power energy consumption and mechanical work output of the actuator samples were measured and/or calculated. The contribution of this study is to present the results on the effect of gold implantation on the actuation performance. To the best of the authors' knowledge, this is the first study focusing on the influence of the metal ions injected into the conducting polymer layers of tri-layer conducting polymer actuators on their actuation ability.

\section{Background on synthesis and operation of electroactive polymer actuators}

Polymers based on pyrrole, thiophene or aniline, which are known as electroactive materials, have been extensively studied to use them as actuators with new functionality and performance [13-15]. Electroactive polymer actuators are classified as internal and external actuators, depending on their electrolyte storage method. For internal actuators there is a passive layer, which stores the electrolyte. For external actuators the electrolyte is stored in an outer cell and the polymer actuator must be partially or fully immersed in the electrolyte. The actuators considered in this study are internal-type conducting polymer actuators.

Polymer actuators used in this study have a multi-layer structure. A full account of the actuator synthesis procedure is presented in [11-13]. The multi-layer actuator structure shows a simple bending motion like a bilayer cantilever beam, as depicted in Fig. 1. Of these layers, the gold-coated PVDF in the centre with a thickness of $110 \mu \mathrm{m}$ is a non-conductive porous membrane used as an electrochemical cell separator, and it also stores the electrolyte (LiTFSI + solvent), facilitating the operation of such conducting polymer actuators in air. The gold layer on each side of the PVDF has approximately $10 \mathrm{~nm}$ thickness. Polypyrrole (PPy) layers, with a thickness of $30 \mu \mathrm{m}$, are electroactive components used as electrodes [14]. The total thickness of the actuators is approximately $170 \mu \mathrm{m}$.

With the electrolyte stored in the PVDF layer, the multi-layer structure forms an electrochemical cell. When a potential difference or current is passed between the PPy layers via the electrical contacts, the whole structure is charged like a capacitor. To maintain charge neutrality within the PPy layers, TFSI $^{-}$anions move from the electrolyte in the middle layer into the positively charged polymer (PPy) electrode and hence cause a volume expansion. At the same time, in the positive electrode/anode, the anions (TFSI ${ }^{-}$) leave the negatively charged electrode as reduction of the PPy 

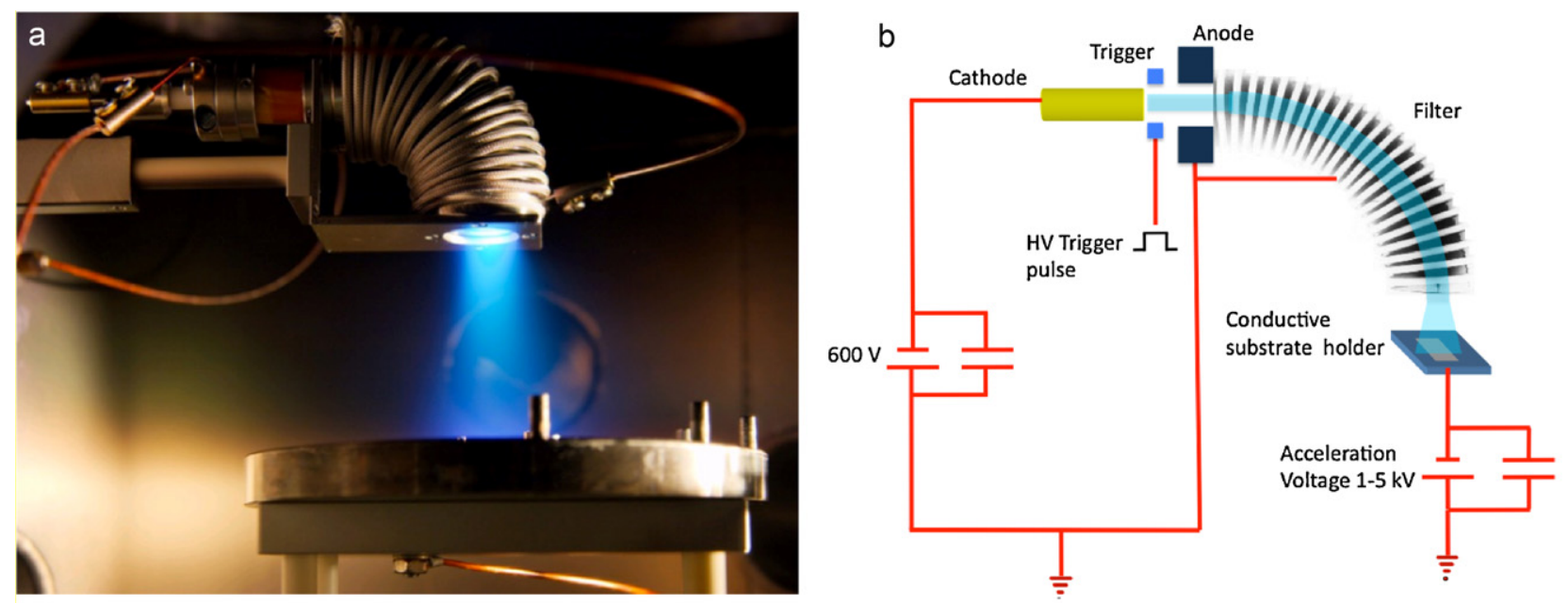

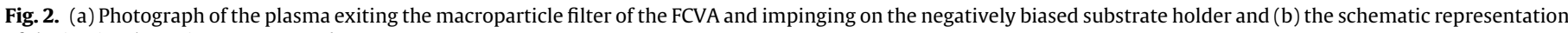
of the ion implantation system used.

From [26].

causes it to become uncharged and a volume contraction occurs. The overall result is that the cantilevered structure will bend towards the negative electrode/cathode, as depicted in Fig. 1. The volume change primarily happens due to the movement of the charge balancing anions in and out of the polymer layers, and perhaps some solvent molecules move inside the polymer layers, due to osmotic effects, to balance the ionic concentration. It is the out of scope of this paper to provide a detailed performance characterization of the actuators. The reader is referred to our [11-15] and other group's [3-7,23] previous work.

\section{Low energy ion implantation}

Ion implantation is commonly used to inject dopants into semiconductors such as silicon in order to modify their electrical properties. The electrical, mechanical, chemical and structural properties of other substrates such as polymers can be significantly changed by the ions inserted beneath their surface. The penetration depth of metallic ions depends on the ion implantation parameters such as the angle of incidence, type of ions, the energy of the ions, and the composition of the target. The higher is the incoming energy of ions, the higher is the penetration depth of the ions into the target of a polymer such as PDMS, as shown for several energies in [26]. Low energies in the range of $50 \mathrm{eV}$ and $5 \mathrm{keV}$ were used to implant gold ions in the first $50 \mathrm{~nm}$ of the PDMS layer in order to make compliant electrodes for dielectric elastomer actu- ators [2,25]. These gold-implanted electrodes can be stretched to strains of up to $175 \%$ while remaining conductive, and, crucially for polymer actuation applications, the implanted electrodes are much less stiff than if the same amount of metal had been sputtered as a continuous film on the polymer. This is due to the resulting microstructure, forming 2-30 nm diameter gold nanoparticle up to $100 \mathrm{~nm}$ below the surface of the polymer, allowing conduction by ohmic contact between nanoparticles that are free to move with respect to each other [26].

The implantation technique used here, which is known as filtered cathodic vacuum arc (FCVA), is a plasma based implantation technique. The details of this ion-implantation technique are presented in [2,25-27]. Its schematic diagram and a photograph during one pulse are depicted in Fig. 2 [26]. It is important to note that in the FCVA implantation technique, the energy of the ions varies within each pulse, the first ions seeing the full potential drop of $2.5 \mathrm{kV}$, while the final ions have energy on the order of $50 \mathrm{eV}$.

\section{Experimental setup}

The experimental setup is to measure the electrochemical behaviour of the actuators consisting of a potentiostat/galvanostat (EG\&G Princeton Applied Research Model 273A), eDAQ e-Corder datalogger unit, and a wave generator connected to the potentiostat unit. The supplied voltage and associated current are recorded by the eDAQ unit interface with a personal computer. The schematic

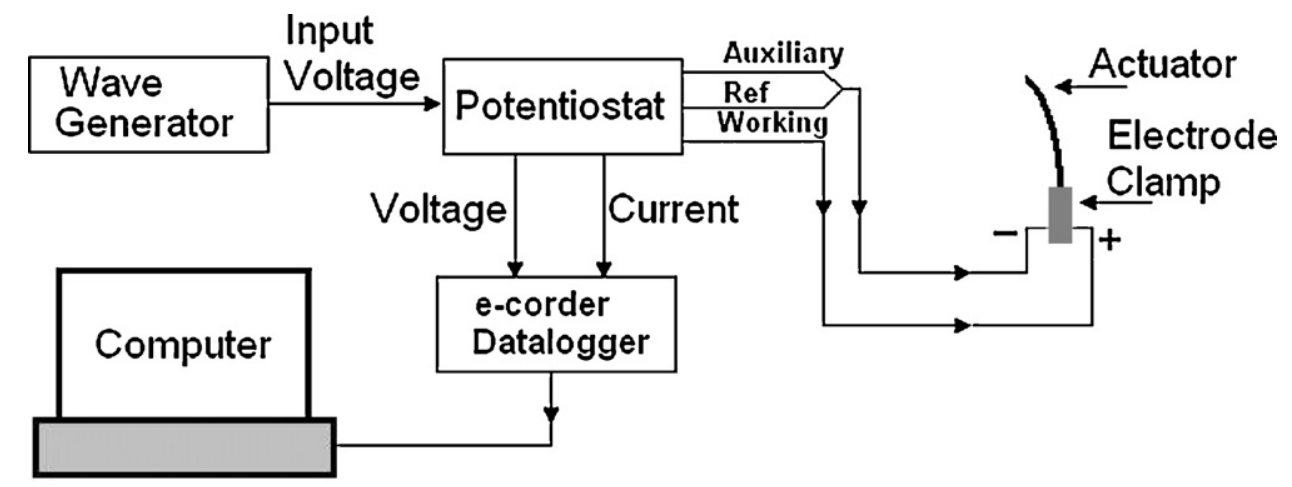

Fig. 3. Schematic diagram of the experimental setup used to stimulate the actuator samples, and to record the associated electrical signals. 

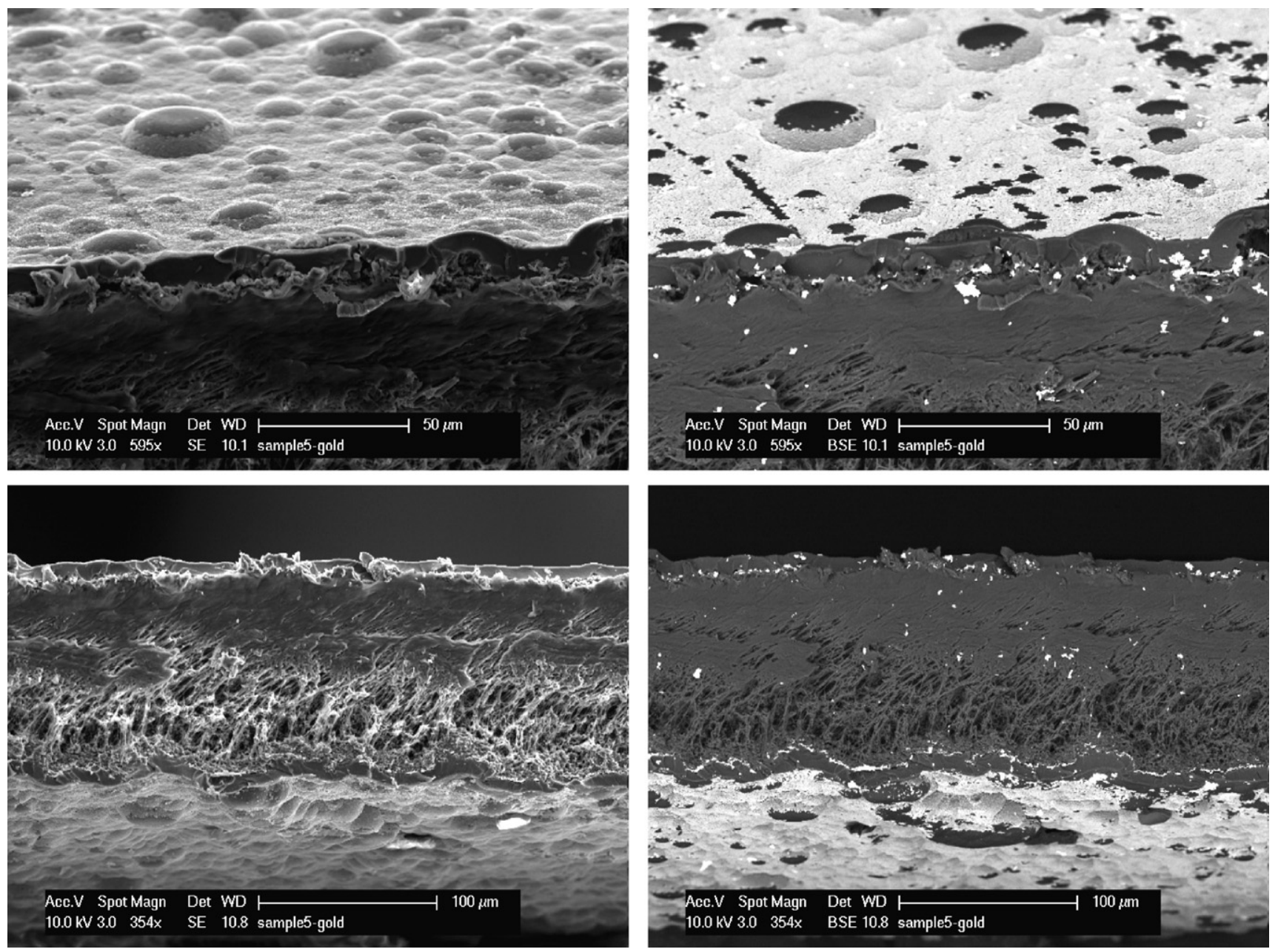

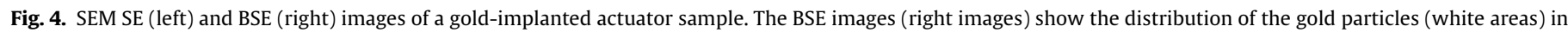
the cross-section between the PVDF and PPy layers, and on the upper and lower surfaces of the actuators.

diagram of this experimental setup is shown in Fig. 3. Autolab PGSTAT12 Potentiostat/Galvanostat equipped with a General Purpose Electrochemical System (GPES) software was employed to form a two electrode cyclic voltammetry (CV) in order to generate CV scans.

The electrode resistance and capacitance of the actuators in different states (normal state, completely dry after gold implantation, and re-wetted with the electrolyte) were measured using an LCR meter (Agilent E4980A Precision LCR Meter) connected with a tweezers like test fixture (Agilent 16334A). The actuator samples were sandwiched in the fixture. The electrode capacitance and resistance were measured using a parallel equivalent circuit mode [24]. The surface resistance of the actuators in different states was measured by a two probe method (the actuators' surface area was too small for the four-probe method) using a digital multi-meter (Keithley 2000 Multimeter).

\section{Experimental results and discussion}

An environmental scanning electron microscope (XL30, ESEMFEG, Philips) was used to generate the secondary electron (SE) images and the backscattered electron (BSE) images of the cross sections of the actuators. The SE and BSE images of a gold implanted actuator sample (Sample 5) are shown in Fig. 4. The images were taken after all experiments were conducted.

When the actuators were implanted with gold ions, a $200 \mu \mathrm{m}$ wide strip on every side was masked off to prevent any short- circuits from one side to the other through the edges of actuator. The top view of an actuator sample (Sample 1) under an optical microscope is shown in Fig. 5, clearly showing the gold implanted area.

The surface resistance of actuator samples with different dimensions is given in Table 1 . These resistance data indicate that the gold-ion implanted samples show factor of 2-3 smaller surface resistance. It is this reduced surface resistance we propose to harness in order to improve the actuation ability of the conducting polymer actuators. The electrode resistance and capacitance of the same actuators were measured using the LCR meter and are provided in Table 2 . These results indicate that while the electrode resistance is decreasing, the electrode capacitance is increasing for the gold implanted samples. These data were measured under an AC voltage signal with amplitude of $1 \mathrm{~V}$ and frequency of $20 \mathrm{~Hz}$ (the minimum this LCR meter can provide). With reference to the surface resistance, and electrode resistance and capacitance measurements, the gold implantation increases the conductivity and the capacitance of the conducting polymer actuators.

One implication of increased capacitance is the increased blocking force or mechanical work output, which are limited for this class of polymer actuators. It was not possible to measure the blocking force, but to estimate the mechanical work output from measured displacement data of samples loaded with $212 \mathrm{mg}$ at the actuator tips. The gold-implanted samples generated more mechanical work output, as presented in Section 5.4. The electrical power consumed by the actuators with and without gold implantation are calculated 
Table 1

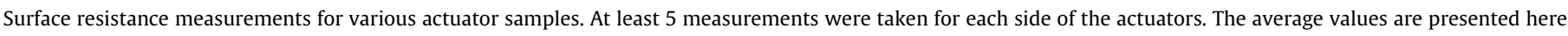

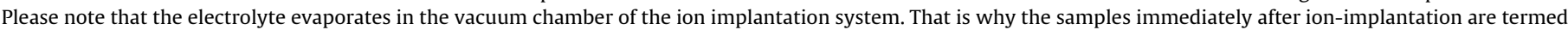
'dry', and these samples are then soaked in the electrolyte prior to testing.

\begin{tabular}{|c|c|c|c|c|}
\hline \multirow[t]{2}{*}{ Samples } & \multicolumn{4}{|c|}{ Surface resistance ( $\Omega$ /square) } \\
\hline & $\begin{array}{l}\text { Filled with } \\
\text { electrolyte (no. } \\
\text { gold } \\
\text { implantation) }\end{array}$ & $\begin{array}{l}\text { Dry-after gold } \\
\text { implantation }\end{array}$ & $\begin{array}{l}\text { Soaked in the } \\
\text { electrolyte } \\
\text { after gold } \\
\text { implantation }\end{array}$ & Comments \\
\hline $\begin{array}{l}\text { Sample } 1 \\
\qquad(15 \mathrm{~mm} \times 3.2 \mathrm{~mm} \times 0.17 \mathrm{~mm})\end{array}$ & 70.4 & 9.28 & 28.04 & The same sample was used for the experiments \\
\hline $\begin{array}{l}\text { Sample } 2 \\
\qquad(18 \mathrm{~mm} \times 3 \mathrm{~mm} \times 0.17 \mathrm{~mm})\end{array}$ & 55.1 & 2.71 & 19.03 & The same sample was used for the experiments \\
\hline $\begin{array}{l}\text { Sample } 3 \\
\qquad(12 \mathrm{~mm} \times 4 \mathrm{~mm} \times 0.17 \mathrm{~mm})\end{array}$ & 47.8 & 3.16 & 19.3 & The same sample was used for the experiments \\
\hline $\begin{array}{l}\text { Sample3_New } \\
\quad(12 \mathrm{~mm} \times 3.8 \mathrm{~mm} \times 0.17 \mathrm{~mm})\end{array}$ & 40.3 & 5.1 & 16.04 & The same sample was used for the experiments \\
\hline $\begin{array}{l}\text { Sample } 4 \\
\qquad(11 \mathrm{~mm} \times 3 \mathrm{~mm} \times 0.17 \mathrm{~mm})\end{array}$ & 41 & 896.5 & 47.4 & $\begin{array}{l}\text { No gold implantation. But, kept in the same } \\
\text { vacuum chamber together with the next sample }\end{array}$ \\
\hline $\begin{array}{l}\text { Sample } 4 \\
\qquad(11 \mathrm{~mm} \times 3 \mathrm{~mm} \times 0.17 \mathrm{~mm})\end{array}$ & 41 & 381.35 & 32.6 & Contact area ( $3 \mathrm{~mm} \times 3 \mathrm{~mm}$ ) only is gold implanted \\
\hline $\begin{array}{l}\text { Sample } 5 \\
\qquad(13 \mathrm{~mm} \times 3 \mathrm{~mm} \times 0.17 \mathrm{~mm})\end{array}$ & 78.37 & 85,000 & 248.6 & $\begin{array}{l}\text { No gold implantation. But, kept in the same } \\
\text { vacuum chamber together with the next sample }\end{array}$ \\
\hline $\begin{array}{l}\text { Sample } 5 \\
\qquad(12 \mathrm{~mm} \times 3 \mathrm{~mm} \times 0.17 \mathrm{~mm})\end{array}$ & 68.9 & 6.5 & 31.04 & Whole surface was gold ion-implanted \\
\hline
\end{tabular}

Table 2

Electrode resistance and capacitance measurements for various actuator samples.

\begin{tabular}{|c|c|c|c|c|}
\hline \multirow[t]{2}{*}{ Samples } & \multicolumn{4}{|c|}{ Resistance $(\Omega)$, capacitance $(\mathrm{nF})$} \\
\hline & $\begin{array}{l}\text { Filled with electrolyte } \\
\text { (no. gold implantation) }\end{array}$ & $\begin{array}{l}\text { Dry-after gold } \\
\text { implantation }\end{array}$ & $\begin{array}{l}\text { Soaked in the } \\
\text { electrolyte after gold } \\
\text { implantation }\end{array}$ & Comments \\
\hline $\begin{array}{l}\text { Sample } 1 \\
\qquad(15 \mathrm{~mm} \times 3.2 \mathrm{~mm} \times 0.17 \mathrm{~mm})\end{array}$ & $1050 \Omega, 110 \mathrm{nF}$ & No data & $40.51 \Omega, 1050 \mathrm{nF}$ & $\begin{array}{l}\text { The same sample was } \\
\text { used for the } \\
\text { experiments }\end{array}$ \\
\hline $\begin{array}{l}\text { Sample } 2 \\
\qquad(18 \mathrm{~mm} \times 3 \mathrm{~mm} \times 0.17 \mathrm{~mm})\end{array}$ & $525 \Omega, 90 \mathrm{nF}$ & No data & $45.8 \Omega, 7000 \mathrm{nF}$ & $\begin{array}{l}\text { The same sample was } \\
\text { used for the } \\
\text { experiments }\end{array}$ \\
\hline $\begin{array}{l}\text { Sample } 3 \\
\qquad(12 \mathrm{~mm} \times 4 \mathrm{~mm} \times 0.17 \mathrm{~mm})\end{array}$ & $2100 \Omega, 85 \mathrm{nF}$ & No data & $38.5 \Omega, 18,615 \mathrm{nF}$ & $\begin{array}{l}\text { The same sample was } \\
\text { used for the } \\
\text { experiments }\end{array}$ \\
\hline $\begin{array}{l}\text { Sample3_new } \\
\qquad(12 \mathrm{~mm} \times 3.8 \mathrm{~mm} \times 0.17 \mathrm{~mm})\end{array}$ & $520 \Omega, 400 \mathrm{nF}$ & No data & $46 \Omega, 10,270 \mathrm{nF}$ & $\begin{array}{l}\text { The same sample was } \\
\text { used for the } \\
\text { experiments }\end{array}$ \\
\hline $\begin{array}{l}\text { Sample } 4 \\
\qquad(11 \mathrm{~mm} \times 3 \mathrm{~mm} \times 0.17 \mathrm{~mm})\end{array}$ & $85 \Omega, 2680 \mathrm{nF}$ & $3 \mathrm{M} \Omega, 267 \mathrm{pF}$ & $150.6 \Omega, 1600 \mathrm{nF}$ & $\begin{array}{l}\text { No gold implantation. } \\
\text { But, kept in the same } \\
\text { vacuum chamber } \\
\text { together with the next } \\
\text { sample }\end{array}$ \\
\hline Sample $4(11 \times 3 \times 0.17 \mathrm{~mm})$ & $84 \Omega, 2720 \mathrm{nF}$ & $0.5 \mathrm{M} \Omega, 1430 \mathrm{pF}$ & $41 \Omega, 14,400 \mathrm{nF}$ & $\begin{array}{l}\text { Contact area } \\
(3 \mathrm{~mm} \times 3 \mathrm{~mm}) \text { only is } \\
\text { gold implanted }\end{array}$ \\
\hline $\begin{array}{l}\text { Sample } 5 \\
\qquad(13 \mathrm{~mm} \times 3 \mathrm{~mm} \times 0.17 \mathrm{~mm})\end{array}$ & $95 \Omega, 2600 \mathrm{nF}$ & $8.0 \mathrm{M} \Omega, 90 \mathrm{pF}$ & $191 \Omega, 1050 \mathrm{nF}$ & $\begin{array}{l}\text { No gold implantation. } \\
\text { But, kept in the same } \\
\text { vacuum chamber } \\
\text { together with the next } \\
\text { sample }\end{array}$ \\
\hline $\begin{array}{l}\text { Sample } 5 \\
\qquad(13 \mathrm{~mm} \times 3 \mathrm{~mm} \times 0.17 \mathrm{~mm})\end{array}$ & $78 \Omega, 3830 \mathrm{nF}$ & $5.5 \mathrm{M} \Omega, 102 \mathrm{pF}$ & $36.9 \Omega, 20,400 \mathrm{nF}$ & $\begin{array}{l}\text { Whole surface was } \\
\text { gold ion-implanted }\end{array}$ \\
\hline
\end{tabular}

\section{Table 3}

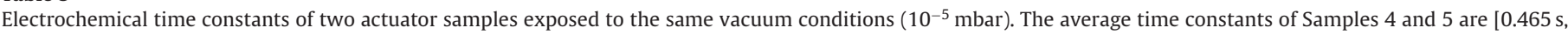
$0.386 \mathrm{~s}$ ] and [0.36 s, $0.337 \mathrm{~s}$, respectively. The average electrical power consumed by Samples 4 and 5 are also calculated.

\begin{tabular}{|c|c|c|c|c|}
\hline Input voltage & $\begin{array}{l}\text { Time constants (s) for } \\
\text { Sample } 4 \text { [normal, with } \\
\text { gold ions] }\end{array}$ & $\begin{array}{l}\text { Average power } \\
\text { consumed by Sample } 4 \\
(\mathrm{~mW})\end{array}$ & $\begin{array}{l}\text { Time constants (s) for } \\
\text { Sample } 5 \text { [normal, with } \\
\text { gold ions] }\end{array}$ & $\begin{array}{l}\text { Average power consumed by } \\
\text { Sample } 5(\mathrm{~mW}) \text { [normal, with gold } \\
\text { ions] }\end{array}$ \\
\hline $0.1 \mathrm{~V}$ & {$[0.4870,0.4160]$} & {$[0.0087,0.0076]$} & {$[0.3750,0.3590]$} & {$[0.0139,0.0095]$} \\
\hline $0.2 \mathrm{~V}$ & {$[0.5610,0.4340]$} & {$[0.0427,0.0391]$} & {$[0.4330,0.3180]$} & {$[0.0621,0.0548]$} \\
\hline $0.3 \mathrm{~V}$ & {$[0.5270,0.4200]$} & {$[0.1013,0.0967]$} & {$[0.4230,0.3470]$} & {$[0.1513,0.1037]$} \\
\hline $0.4 \mathrm{~V}$ & {$[0.4640,0.3920]$} & {$[0.2425,0.4581]$} & {$[0.3390,0.2960]$} & {$[0.2740,0.1972]$} \\
\hline $0.5 \mathrm{~V}$ & {$[0.4220,0.3960]$} & {$[0.3958,0.2996]$} & {$[0.3420,0.3390]$} & {$[0.4611,0.3167]$} \\
\hline $0.6 \mathrm{~V}$ & {$[0.4010,0.3500]$} & {$[0.5990,0.4536]$} & {$[0.3350,0.3280]$} & {$[0.6565,0.4923]$} \\
\hline $0.7 \mathrm{~V}$ & {$[0.4880,0.3470]$} & {$[0.7676,0.6455]$} & {$[0.3350,0.3700]$} & {$[0.9999,0.6795]$} \\
\hline $0.8 \mathrm{~V}$ & {$[0.3730,0.3360]$} & {$[1.1198,0.8823]$} & {$[0.2940,0.3350]$} & {$[1.3609,0.9601]$} \\
\hline
\end{tabular}



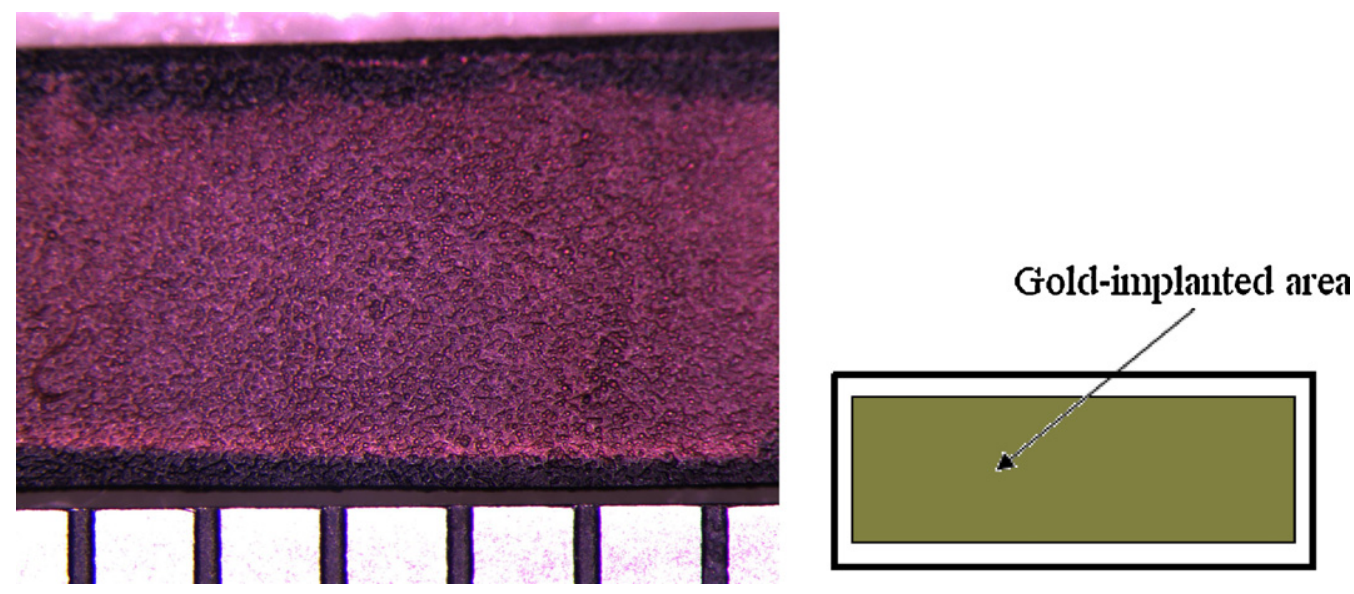

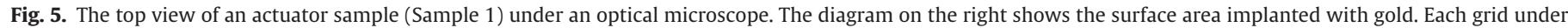
the left image indicates $1 \mathrm{~mm}$.

and presented in Table 3 . These results show that the power consumption is reduced for the gold implanted samples due to their improved conductivity.

\subsection{Measurement of actuator time constant}

To further demonstrate the effect of the gold ion implantation on the actuation ability of the actuators, the RC time constant of the actuator samples are identified from current versus time curves. The form of the current-time curve is similar to the charging curve of a capacitor. The time constant to be identified from the current curve indicates how fast the actuator is charged under a given potential difference. The current curve is described by:

$I=I_{\max } e^{-t / \tau}$

where $\tau$ is the charging time (RC) constant of the actuator. It is the time corresponding to $36.8 \%$ of the peak current. Using this definition of the time constant in Fig. 6, the time constant of the actuator samples under a range of step input voltages are estimated from the experimental current versus time curves, and are depicted in Table 3. Typical current responses, for example, from Sample 5 with and without gold ion implantation are shown in Fig. 7. The current flow during the electrochemical actuation is due to the charge taken off or placed in the primary chain of the polymer to have charge neutrality.

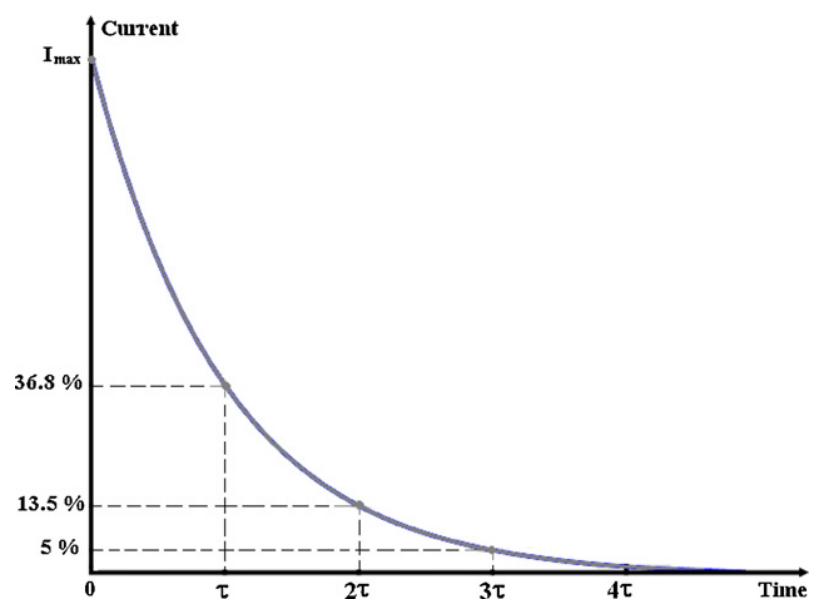

Fig. 6. Definition of electrochemical time constant based on the current response of the actuators.
As given in Table 3, the time constants vary with the input voltage, though not significantly. This is expected as the oxidation level or the charge injection is input voltage-dependent. The goldimplanted samples have a smaller time constant, which indicates a higher response speed.

\subsection{Effect of ion implantation conditions (i.e., vacuum) on current response}

Samples 1-3 were prepared differently than samples 4 and 5 . For Sample 1, Sample 2, Sample 3, Sample 3-New, each sample was tested under a range of input voltages $( \pm 0.1-0.8 \mathrm{~V}$ with steps of $\pm 0.1 \mathrm{~V}$ and a period of $80 \mathrm{~s}$ ), and was then gold-ion implanted in a vacuum chamber. That is to say, the actuator samples without gold implantation were not exposed to high vacuum, which causes the solvent from the electrolyte to evaporate. As presented in the next paragraph, the vacuum in the ion implantater leads to a 8-9\% reduction of the actuator length. When the actuators exposed to the vacuum were re-soaked in the electrolyte, they recovered their initial dimensions. The surface resistance, electrode resistance, and electrode capacitance of actuators exposed to vacuum (completely dry) were measured to be on the order of $2500 \Omega, 4.0 \mathrm{G} \Omega$, and $70 \mathrm{fF}$, respectively. On the other hand, the actuator samples with gold implantation, still dry, have more favorable electrical properties, as given in Tables 1 and 2 .

To evaluate the effect of the vacuum on the time constant of the actuators, a new sample with the dimensions of $12 \mathrm{~mm} \times 3.8 \mathrm{~mm} \times 0.17 \mathrm{~mm}$ was tested before it was kept in the vacuum for the duration ( $\sim 20 \mathrm{~min}$ at $\left.10^{-5} \mathrm{mbar}\right)$ used to implant gold in the actuator samples. Not only the time constant of the actuator was increased, but also the peak current was decreased, as shown in Table 4, and in Fig. 8. This experiment was repeated 4 times to minimize measurement errors.

\section{Table 4}

Electrochemical time constants and peak currents of an actuator sample exposed to a vacuum, and not exposed to the vacuum under step inputs with a period of $80 \mathrm{~s}$.

\begin{tabular}{lll}
\hline Input voltage & $\begin{array}{l}\text { Time constants }(\mathrm{s})[\mathrm{no} \\
\text { vacuum, after vacuum } \\
(\%) \text { increase }]\end{array}$ & $\begin{array}{l}\text { Maximum currents } \\
(\mathrm{mA})[\text { no vacuum, after } \\
\text { vacuum, }(\%) \text { decrease }]\end{array}$ \\
\hline $0.1 \mathrm{~V}$ & {$[0.5480,0.7090,29.38]$} & {$[7.3371,6.1708,15.90]$} \\
$0.3 \mathrm{~V}$ & {$[0.5430,0.6670,22.84]$} & {$[14,19,23]$} \\
$0.5 \mathrm{~V}$ & {$[0.5900,0.7150,21.19]$} & {$[36.0031,31.7028$,} \\
& & $11.94]$ \\
$0.8 \mathrm{~V}$ & {$[0.6340,0.7410,16.88]$} & {$[53.4027,47.3846$,} \\
& & $11.27]$ \\
\hline
\end{tabular}



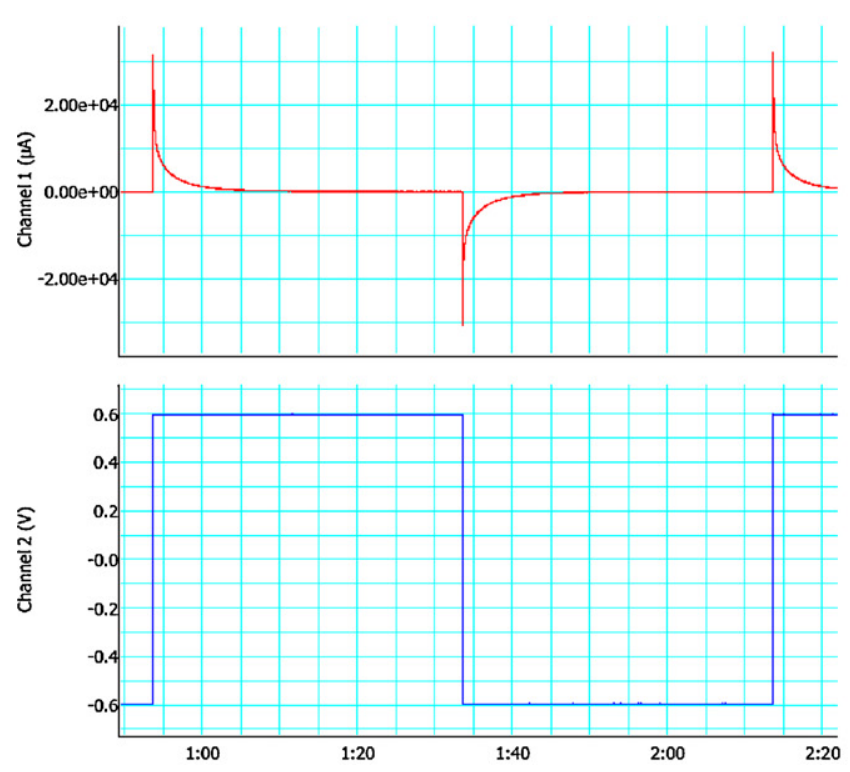
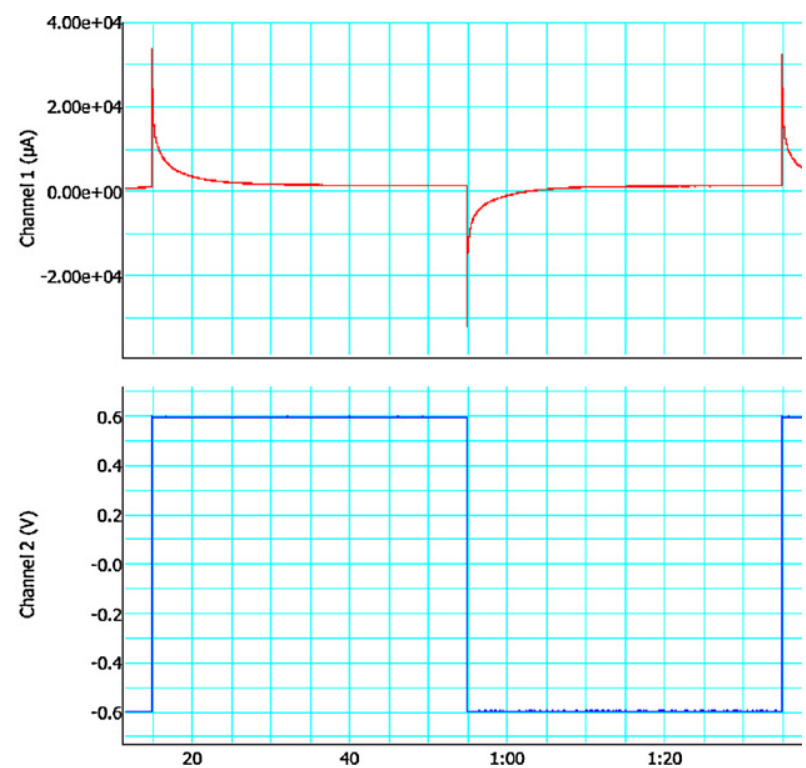

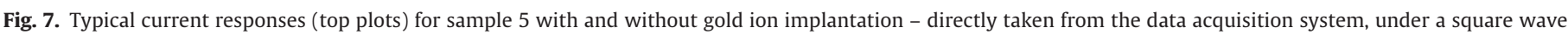
input of $\pm 0.6 \mathrm{~V}$ (bottom plots) with a period of $80 \mathrm{~s}$.

\subsection{Effect of ion implantation on work output of actuators}

To quantify the work output of the actuator samples, 4 cylindrical permanent magnets with the dimensions of $3 \mathrm{~mm}$ in diameter, $1 \mathrm{~mm}$ in thickness, and a total mass of $212 \mathrm{mg}$ were attached to the tip of each actuator sample with or without gold implantation. The actuators movements were recorded with a digital camera to determine the vertical movement of the tip load. The images for the actuator samples are provided in Fig. 9. The total work output $W_{\mathrm{o}}$ is the sum of the elastic potential energy $V_{\mathrm{e}}$ to bend the loaded cantilevered actuator from the start position to the final position, and the gravitational potential energy $V_{\mathrm{g}}$ to lift the tip load from the start position to the final position under the given voltage input:

$W_{\mathrm{o}}=V_{\mathrm{e}}+V_{\mathrm{g}}=\frac{1}{2} k \delta^{2}+m g \delta, \quad k=\frac{m g}{\delta_{\mathrm{i}}}$

where $\delta_{\mathrm{i}}$ is the deflection of the actuator under the tip load when the actuators are inactivated. The mechanical stiffness constant of the actuators is calculated from Hooke's law-the tip load is simply divided by the tip deflection $\left|\delta_{\mathrm{i}}\right|$ under the tip load of four magnets.
From the top left image of Fig. $9, \delta_{\mathrm{i}}=2.8 \mathrm{~mm}$, and from the top right image, $\delta_{\mathrm{f}}=3.2 \mathrm{~mm}$. The mechanical stiffness of this sample (Sample 4) with a gold coating in the surface area of $3 \mathrm{~mm} \times 3 \mathrm{~mm}$ (the area corresponding to the area of the electrical contacts) is $0.743 \mathrm{~N} / \mathrm{m}$. The total work output is calculated from Eq. (2) as $W_{0}=25.85 \mu \mathrm{J}$. From the bottom left image, $\delta_{\mathrm{i}}=5.636 \mathrm{~mm}$, and from the bottom right image $\delta_{\mathrm{f}}=1 \mathrm{~mm}$. Using these data, the mechanical stiffness of the sample with no gold implantation is $0.369 \mathrm{~N} / \mathrm{m}$. The total work output for an actuator with no gold (Sample 4) is calculated as $W_{\mathrm{o}}=21.93 \mu \mathrm{J}$, showing with a $15 \%$ decrease in the work output.

For the work output of Sample 5 under $0.5 \mathrm{~V}$, from the top left image of Fig. $10, \delta_{\mathrm{i}}=2.67 \mathrm{~mm}$, and from the right image $\delta_{\mathrm{f}}=2.89 \mathrm{~mm}$. The mechanical stiffness of Sample 5 with full gold coating is $0.7085 \mathrm{~N} / \mathrm{m}$. The total work output is calculated as $W_{\mathrm{o}}=22.51 \mu \mathrm{J}$. From the bottom left image of Fig. $10, \delta_{\mathrm{i}}=5.647 \mathrm{~mm}$, and from the right image $\delta_{\mathrm{f}}=-2.82 \mathrm{~mm}$. Using these data, the mechanical stiffness of Sample 5 with no gold implantation is $0.335 \mathrm{~N} / \mathrm{m}$. The total work output is calculated as $W_{0}=8.22 \mu \mathrm{J}$ with a $63.5 \%$ decrease in the work output. This is a significant work out-
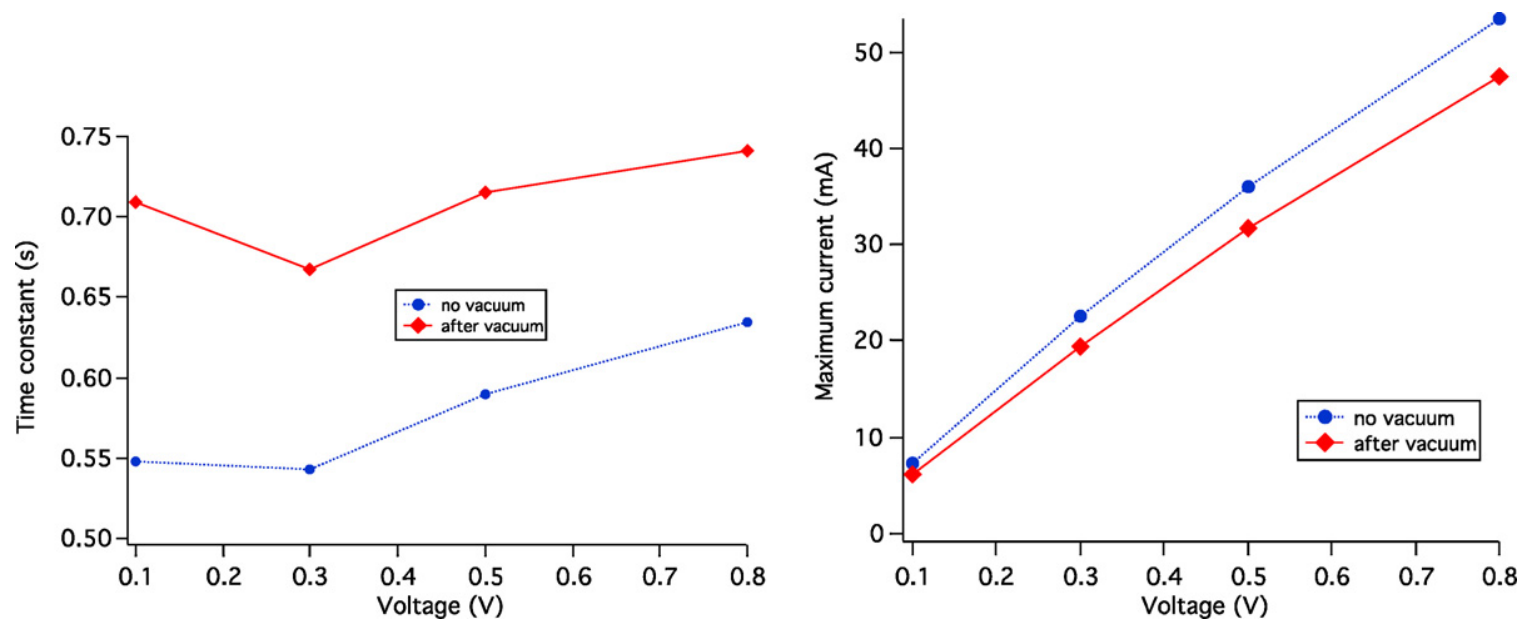

Fig. 8. The effect of the ion-implantation conditions on the current response of the actuators. 

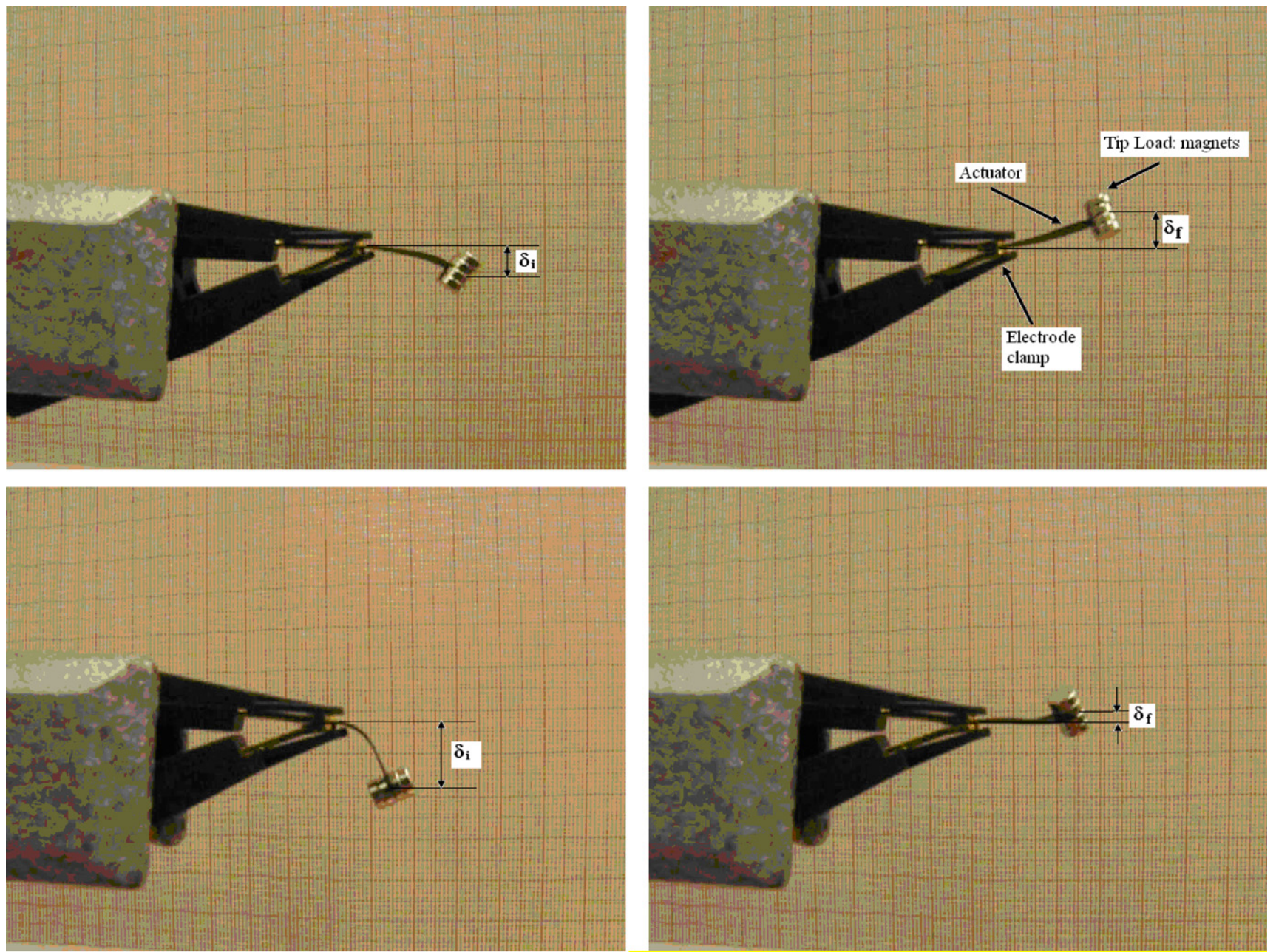

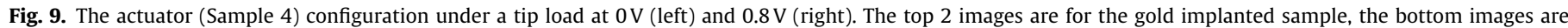
non-implanted.

put difference between a gold implanted and no gold implanted samples.

This analysis of the experimental data for Samples 4 and 5 shows that the samples implanted with gold ions generate more mechanical work output than the same samples without gold implantation under the same potential difference. Further, with reference to the electrical power consumed by the gold implanted samples in Table 3, this mechanical work output is generated with a lower electrical power. This follows that the gold ion implantation contributes to the efficiency of these actuators, which is well below $1 \%$.

To further evaluate the effect of ion implantation conditions on the work output of the actuators, the work output of the actuator sample with the current response data presented in Table 4 is calculated under $0.8 \mathrm{~V}$. From the top left image of Fig. $11, \delta_{\mathrm{i}}=7 \mathrm{~mm}$, and from the top right image $\delta_{\mathrm{f}}=3 \mathrm{~mm}$. The mechanical stiffness of this untreated (not exposed to the gold implantation condition) actuator sample is calculated as $0.297 \mathrm{~N} / \mathrm{m}$. The total work output is calculated from Eq. (2) as $W_{0}=35.65 \mu \mathrm{J}$. From the bottom left image of Fig. $11, \delta_{\mathrm{i}}=6.76 \mathrm{~mm}$, and from the right image $\delta_{\mathrm{f}}=1.96 \mathrm{~mm}$. Using these data, the mechanical stiffness of the same sample exposed to the gold implantation conditions is $0.3075 \mathrm{~N} / \mathrm{m}$. The total work output is calculated as $W_{0}=29.83 \mu \mathrm{J}$, which is $16.3 \%$ less than the work output of the untreated actuator sample. This follows that while the ion implantation enhances the work output of the actuators, it stiffens the devices, limiting actuation range for a given voltage.
The displacement responses of Sample 5 with and without gold implantation were generated under $0.5 \mathrm{~V}$ to evaluate the time constant of this electrochemomechanical response. They are shown in Fig. 12 that the gold implanted sample showed a faster response with a time constant of $1.58 \mathrm{~s}$, compared to the time constant $(2.20 \mathrm{~s})$ of the bare Sample 5 without gold implantation. This also supports the conclusion that the gold implanted samples have a higher response speed compared to the actuators without gold implantation.

As stated above, the gold implantation increases the stiffness of the actuators. This can be quantified by calculating the flexural rigidity of the actuators, which is a function of the modulus of elasticity and the area moment of inertia. The area moment of inertia is calculated using the equivalent width approach, in which the widths of the layers with the higher modulus of elasticity are expanded to bring the whole structure into a single material of the lower modulus of elasticity [28]. To maintain the same flexural rigidity, the width of the layer with the higher modulus of elasticity is increased by $n=E_{2} / E_{1}, E_{2}>E_{1}$. It has been reported [29] that the moduli of elasticity of PPy and PVDF layers for the bare actuator used in this study are approximately $190 \mathrm{MPa}$ and $117 \mathrm{MPa}$, respectively. This follows that $n=E_{\mathrm{PPy}} / E_{\mathrm{PVDF}}=1.624$, and the width of the PPy layers, for example, in Sample 5, is increased by ' $n$ ' to $4.872 \mathrm{~mm}$ (the original width is $3 \mathrm{~mm}$ ) for an actuator without any gold implantation. The new cross-section consisting of a single material PVDF is presented in Fig. 13. Similarly, for the actuator (Sample 

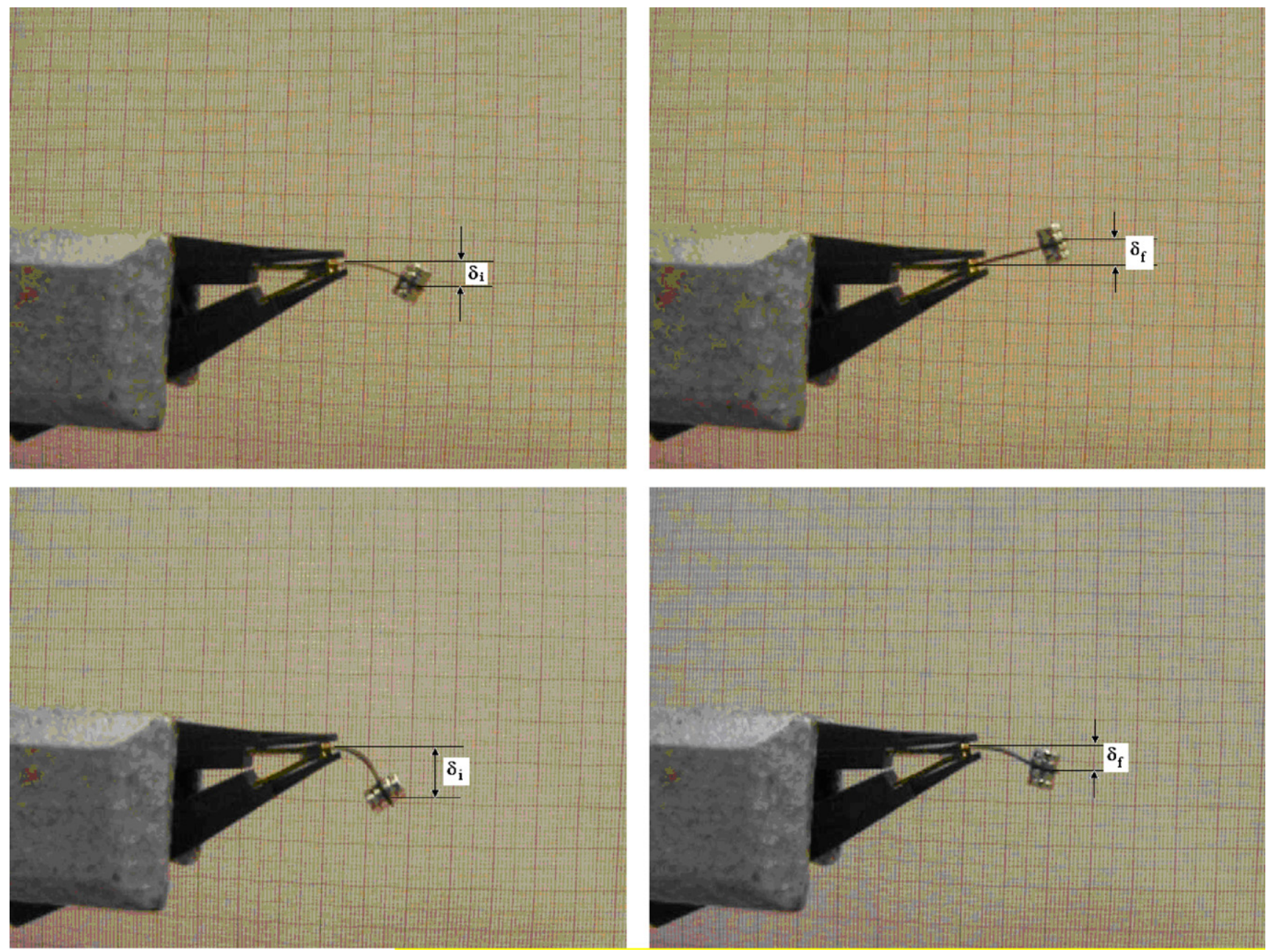

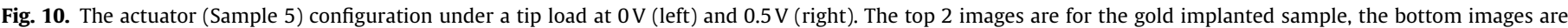
non-implanted.

5) with the gold implantation, $\bar{n}=E_{\mathrm{Au}} / E_{\mathrm{PVDF}}=675.214$, where $E_{\mathrm{Au}}=79 \mathrm{GPa}$. The width of the implanted Au layers is increased by ' $\bar{n}$ ' to $2025.6 \mathrm{~mm}$ (the original width is $3 \mathrm{~mm}$ ) for the gold implanted actuators. The new cross section consisting of a single material, which is the PVDF, is presented in the right most cross-section in Fig. 13.

For the bare actuator (Sample 5) with the dimensions of $t_{1}=30 \mu \mathrm{m}$, and $t_{2}=110 \mu \mathrm{m}$ and $\bar{b}_{1}=b \times n=3 \times 1.624 \mathrm{~mm}$, the area moment of inertia is calculated as $I_{\text {bare }}=904.02 \times 10^{-6} \mathrm{~mm}^{4}$. For the actuator with the gold implantation, the other dimensions are the same except $t_{1}=29.9 \mu \mathrm{m}$ and $t_{\text {gold }}=100 \mathrm{~nm}$ (assumed value). The area moment of inertia is calculated as $I_{\text {gold }}=3827.6 \times 10^{-6} \mathrm{~mm}^{4} . I_{\text {gold }}>I_{\text {bare }}$, which explains the stiffening effect of the gold implantation. This increased area moment inertia will create smaller bending stress, which further demonstrates the stiffening effect of the gold implantation, as expressed by the bending stress $\sigma$ calculated from:

$\sigma=\frac{M c}{I}$

where the area moment of inertia $I$ is for the new cross section, ' $c$ ' is the half of the total thickness, and $M$ is the internal bending moment generated due to the electrochemical process. Because the active layers of both actuators are the same, they are expected to generate the same internal bending moment under the same input voltage.

\subsection{Electrochemical characterization of gold implanted samples}

Autolab PGSTAT12 Potentiostat/Galvanostat equipped with A General Purpose Electrochemical System (GPES) software was employed to form a two electrode cyclic voltammetry, which is a commonly used measurement to characterize the electrochemical behaviour of the actuators. It is normally measured in a threeelectrode setup. However, in this study, it is generated in a two electrode setup to look at the electrochemical behaviour of the actuators-the counter and reference electrodes are short-circuited and connected to one electrode of the actuators, the working electrode to the other electrode of the actuators, like shown in Fig. 3. The CV scans of some of the actuator samples in Table 1 are shown in Fig. 14. The scans were generated under $-0.8 \mathrm{~V}$ to $+0.8 \mathrm{~V}$ with a range of scan rates $(10,20,40,60,100 \mathrm{mV} / \mathrm{s})$.

When the shape of a CV scan is close to a rectangle, it indicates a capacitive behaviour. A rectangular-shaped CV is a typical characteristic of an ideal double-layer capacitor, which our actuator structure and operation principle resemble. As shown in Fig. 14, the ion-implanted actuators behave like a capacitor over a large voltage range, especially when the scan rates are low. This indicates that the actuators capacitively store most of the electrical energy. When the scan rates are higher $>60 \mathrm{mV} / \mathrm{s}$, they show a resistive behaviour-most of the electrical energy is dissipated due to the electrolyte resistance, and the movement of ions in and out of the polymer layers. Each scan was repeated at least 10 times. The gold implanted actuators have shown repeatable scans, almost no devi- 

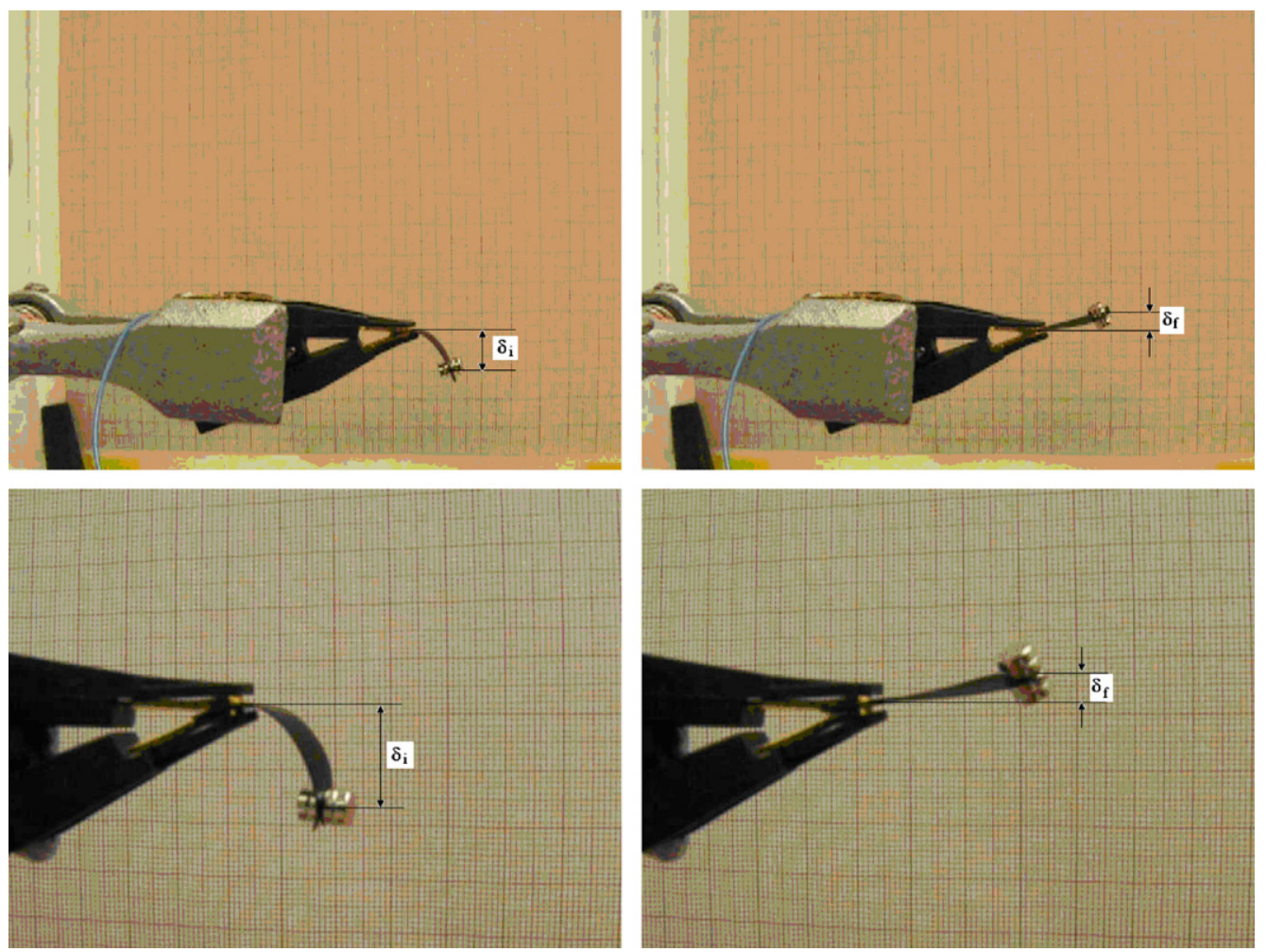

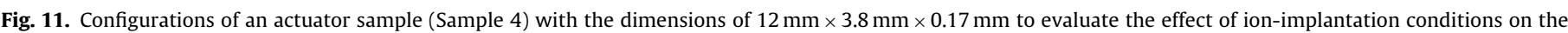

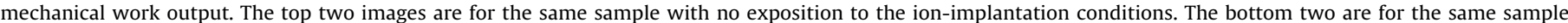

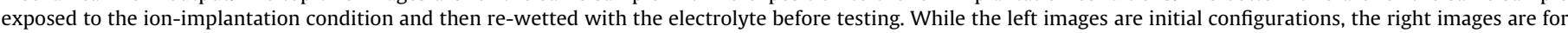
the activated configurations.
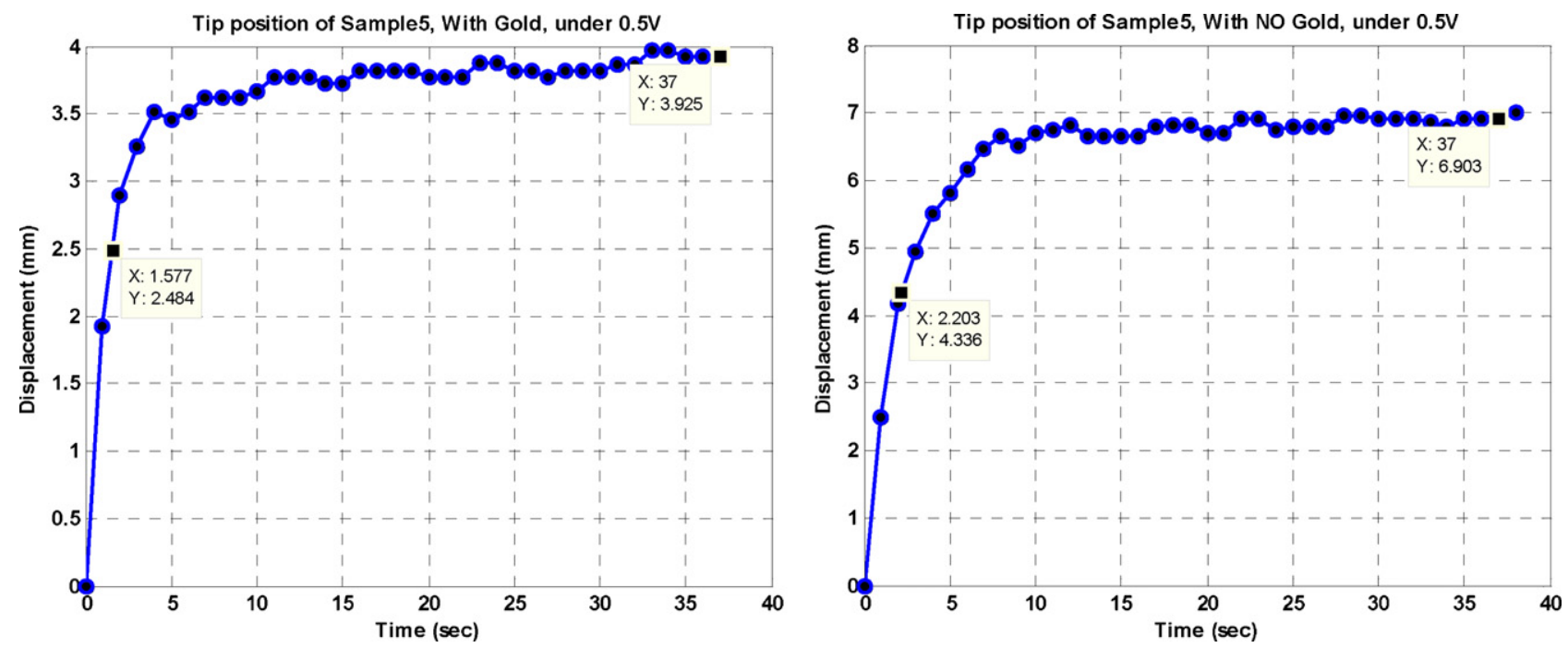

Fig. 12. Displacement response of Sample 5 with (left plot) and without (right plot) gold implantation under $0.5 \mathrm{~V}$.
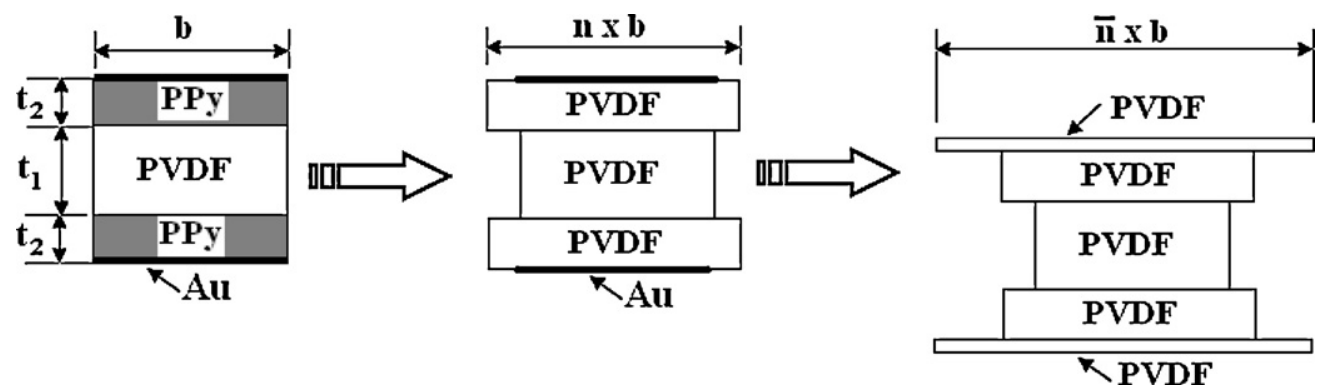

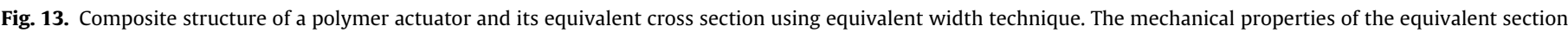
with a single material are equivalent to that of the original multi-material structure. 

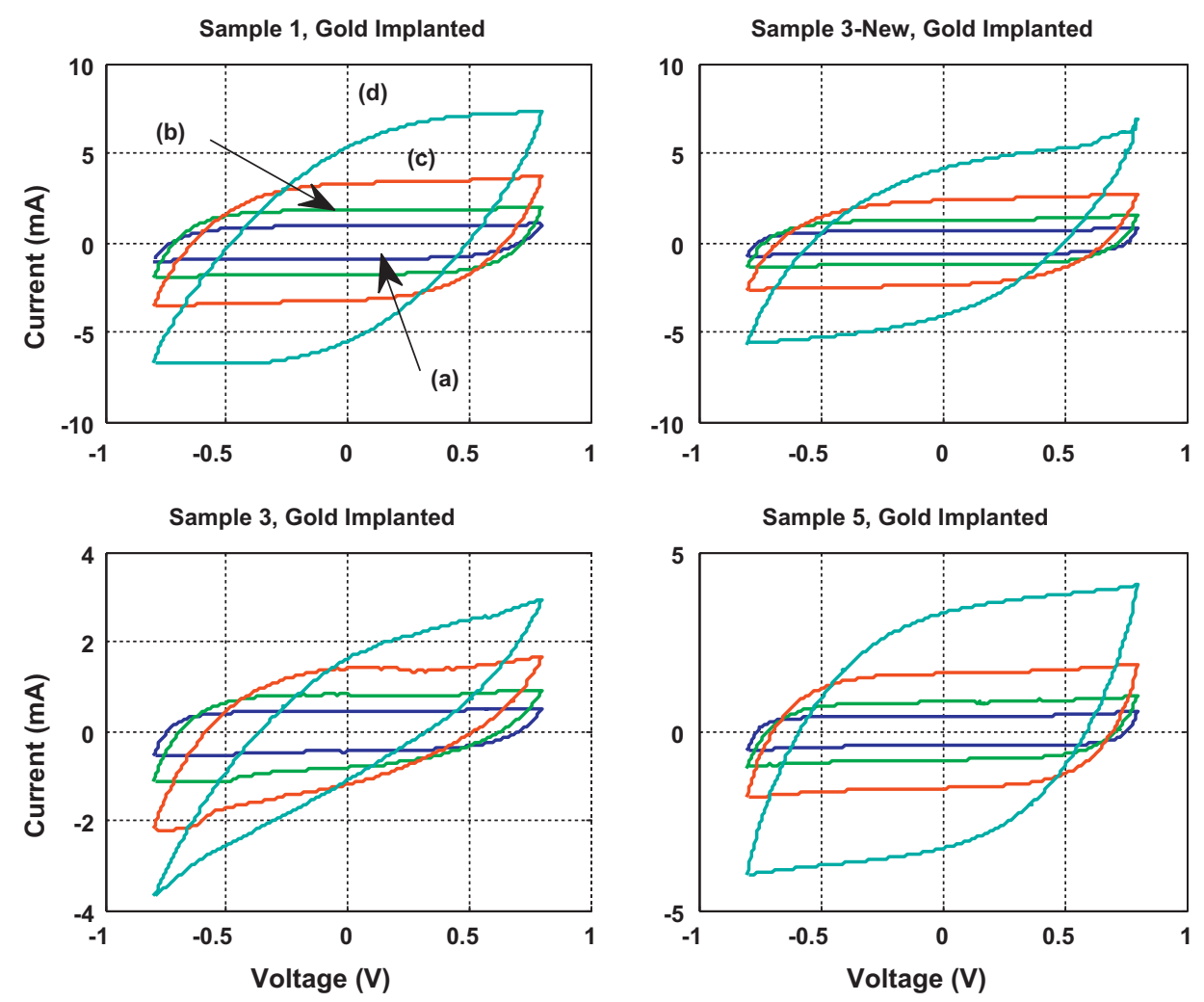

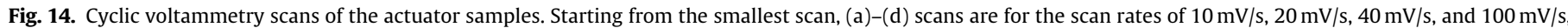
respectively.

ation between the first scan and the last scan for all scan rates. The same consistency was not observed for the bare actuators.

To be able to distinguish the effects due to gold implantation from simply the effect of vacuum on the electrolyte, CV scans of the actuator sample in Table 4 were taken and are presented in Fig. 15. The charges injected into the actuator before it was exposed to the vacuum (top plot of Fig. 11) are calculated as $113.4 \mathrm{mC}, 105.7 \mathrm{mC}$ $97.71 \mathrm{mC}$, and $83.51 \mathrm{mC}$ for the scan rates of $20 \mathrm{mV} / \mathrm{s}, 40 \mathrm{mV} / \mathrm{s}$, and
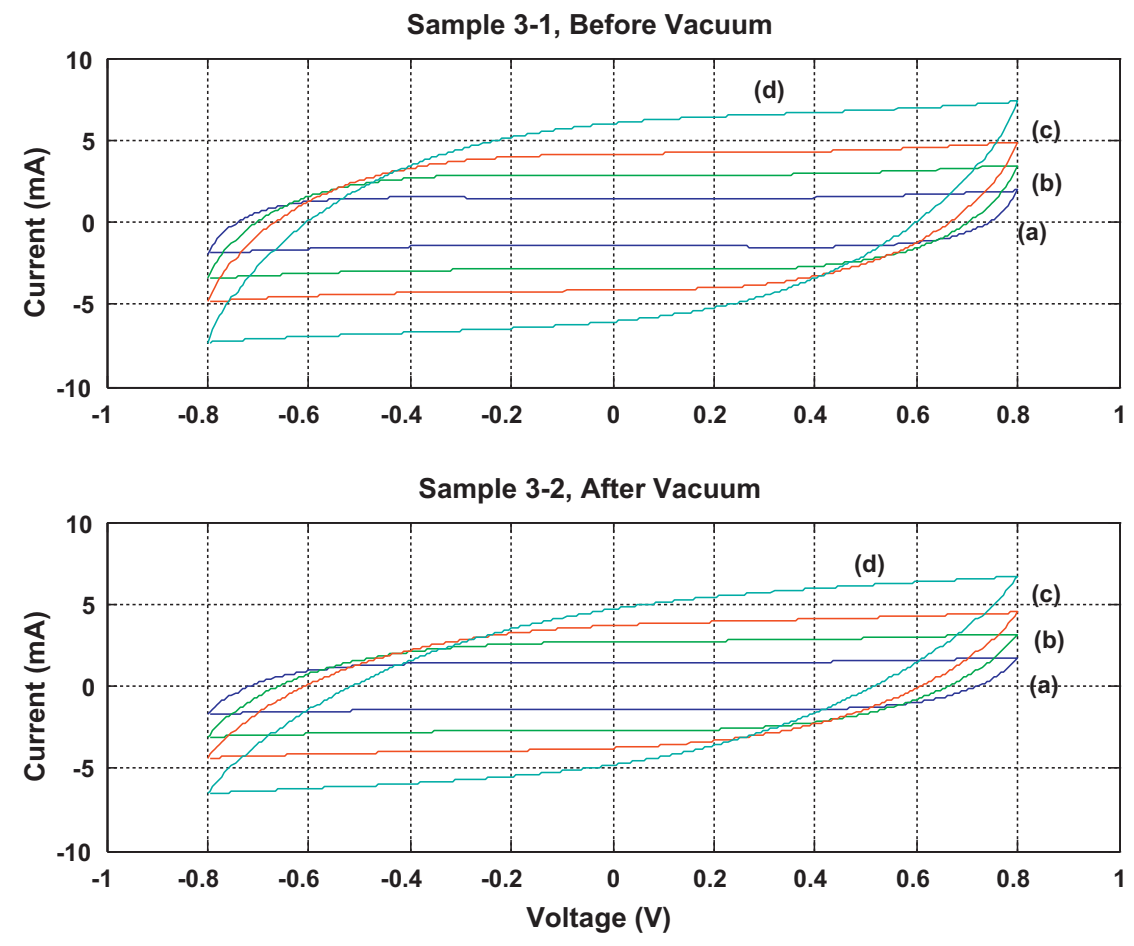

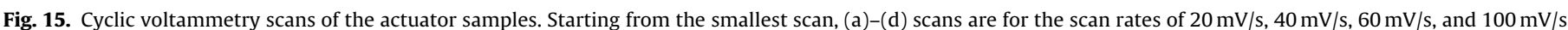
respectively. 
$60 \mathrm{mV} / \mathrm{s}, 100 \mathrm{mV} / \mathrm{s}$, respectively. On the other hand, the charges injected into the same sample, but exposed to the vacuum (bottom plot) are $106.3 \mathrm{mC}, 95.67 \mathrm{mC}, 85.75 \mathrm{mC}$, and $69.41 \mathrm{mC}$, respectively, for the same scan rates. The vacuum conditions reduce the charge stored in the actuators. This may be due to the reduced size of the porosities in the actuator. In contrast, the implantation allows for larger charge storage since there are fewer ohmic losses.

\section{Conclusions and future work}

We have presented the first experimental results to quantify the effect of gold ion implantation on the actuation performance of ionic-type conducting polymer actuators. The results demonstrate that the conductivity of the actuators increases noticeably, which leads to increased charge injected into the polymer layers, faster time injection, increased mechanical work output, and modified their electrochemical behaviour. Another important finding is that the ion-implantation conditions (vacuum) do have a detrimental effect on the actuator performance, which can be mostly recovered by placing the device in an electrolyte bath. Any residual damage is more than counter-balanced by the improvement brought by the gold ions injected beneath the outer surfaces of the actuators counter. While the gold implanted actuators had a higher mechanical stiffness, and therefore a smaller displacement output, their time constant is smaller, indicating a higher response speed. Future work involves measuring the blocking force, optimizing the gold ion-implantation conditions such as the number of pulses, pulse dosage, a comprehensive investigation on the chemical, electrical and mechanical properties of these actuators and other ionic-type conducting polymer actuators and sensors. It must be noted that the gold implantation is permanent and can be used to make bilayer microactuators, for which the delamination of a gold layer is a significant problem [20,21]. The gold implantation can also be used to increase the conductivity and the capacitance of super-capacitors based on conducting polymers.

\section{Acknowledgements}

This research has been supported by Australian Research Council through an ARC Discovery Project (Grant no. DP0878931), and ARC Centre of Excellence for Electromaterials Science (Grant no. CE0561616). Financial support from the Swiss National Science Foundation Grant 200020-130453, and from the Indo-Swiss Joint Research Programme (IJSRP) grant \#122948 is gratefully acknowledged. The authors thank Dr Babita Gaihre, Dr Peter van der Wal, Dr Massoud Dadras, Mrs Mireille Leboeuf, Dr Caglar Ataman, and Mrs Samin Akbari for their technical help, comments and suggestions during this study.

\section{References}

[1] S. Ashley, Artificial muscles, Scientific American 289 (4) (2003) 52-59.

[2] S. Rosset, M. Niklaus, P. Dubois, H.R. Shea, Large-stroke dielectric elastome actuators with ion-implanted electrodes, IEEE Journal of Microelectromechanical Systems 18 (December (6)) (2009) 1300-1308.

[3] E. Smela, Conjugated polymer actuators, MRS Bulletin 33 (3) (2008) 197-204.

[4] G.M. Spinks, G. Alici, S. McGovern, B. Xi, G.G. Wallace, Fundamental mechanisms of actuation in conducting polymers, in: F. Carpi, E. Smela (Eds.), A Chapter in Biomedical Applications of Electroactive Polymer Actuators, John Wiley \& Sons, Ltd., 2009, pp. 195-228.

[5] R.H. Baughman, Conducting polymer artificial muscles, Synthetic Metals 78 (1996) 339-353.

[6] G.G. Wallace, G.M. Spinks, L.A.P. Kane Maguire, P.R. Teasdale, Conductive Electroactive Polymers, Intelligent Materials Systems, 3rd ed., CRC Press, Boca Raton, FL, 2009.

[7] J.D. Madden, R.A. Cush, T.S. Kanigan, I.W. Hunter, Fast contracting polypyrrole actuators, Synthetic Metals 113 (2000) 185-192.

[8] G. Alici, G. Spinks, N.N. Huynh, L. Sarmadi, R. Minato, Establishment of a biomimetic device based on tri-layer polymer actuators-propulsion fins: establishment of a biomimetic device, Journal of Bioinspiration \& Biomimetics 2 (2007) S18-S30.

[9] S. McGovern, G. Alici, V.-T. Truong, G. Spinks, Finding NEMO (novel electromaterial muscle oscillator): a polypyrrole powered robotic fish with real-time wireless speed and directional control, Smart Materials and Structures 18 (9) (2009) 095009

[10] G. Alici, M.J. Higgins, Normal stiffness calibration of microfabricated tri-layer conducting polymer actuators, Smart Materials and Structures 18 (2009) 065013.

[11] G.M. Spinks, B. Xi, D. Zhou, V. Truong, G.G. Wallace, Enhanced control and stability of polypyrrole electromechanical actuators, Synthetic Metals 140 (2-3) (2004) 273-280.

[12] Y. Wu, G. Alici, G.M. Spinks, G.G. Wallace, Fast tri-layer polypyrrole bending actuators for high speed applications, Synthetic Metals 156 (16-17) (2006) 1017-1022.

[13] G. Alici, V. Devaud, P. Renaud, G.M. Spinks, Conducting polymer microactuators operating in air, Journal of Micromechanics and Microengineering 19 (2009) 025017.

[14] G. Alici, N.N. Huynh, Predicting force output of trilayer polymer actuators, Sensors and Actuators 132 (2) (2006) 616-625.

[15] R. Mutlu, G. Alici, A multi-stable linear actuation mechanism based on artificial muscles, ASME Journal of Mechanical Design 132 (11) (2010).

[16] S. Saher, W. Kim, S. Moon, H.J. Kim, Y.H. Kim, Electro-actuation characteristics of $\mathrm{Cl}_{2}$ and $\mathrm{SF}_{6}$ plasma-treated IPMC actuators, Smart Materials and Structures 10 (2010) 105013.

[17] M. Shahinpoor, K.J. Kim, The effect of surface-electrode resistance on the performance of ionic polymer-metal composite (IPMC) artificial muscles, Journal of Smart Materials and Structures 9 (2000) 543-551.

[18] U. Johanson, U. Maeorg, V. Sammelselg, D. Brandell, A. Punning, M. Kruusmaa, A. Aabloo, Electrode reactions in Cu-Pt coated ionic polymer actuators, Sensors and Actuators: B 131 (2008) 340-346.

[19] A. Punning, M. Kruusmaa, A. Aabloo, Surface resistance experiments with IPMC sensors and actuators, Sensors and Actuators A 133 (2007) 200-209.

[20] E. Smela, Conjugated polymer actuators for biomedical applications, Advanced Materials 15 (6) (2003) 481-494.

[21] E.W.H. Jager, O. Inganas, I. Lunstrom, Microrobots for micrometer-size objects in aqueous media: potential tools for single cell manipulation, Science 288 (2000) 2335-2338.

[22] M. Kujawski, J.D. Pearse, E. Smela, Elastomers filled with exfoliated graphite as compliant electrodes, Carbon 48 (2010) 2409-2419.

[23] X. Wang, B. Shapiro, E. Smela, Development of a model for charge transport in conjugated polymers, Journal of Physical Chemistry 113 (1) (2009) 382-401.

[24] Users Manual, Agilent E4980A Precision LCR Meter, 8th ed., June 2010, pp. 55 and 198.

[25] S. Rosset, M. Niklaus, P. Dubois, H.R. Shea, Metal ion implantation for the fabrication of stretchable electrodes on elastomers, Advanced Functional Materials 19 (3) (2009) 470-478.

[26] M. Niklaus, H.R. Shea, Electrical conductivity and Young's modulus of flexible nanocomposites made by metal-ion implantation of polydimethylsiloxane: the relationship between nanostructure and macroscopic properties, Acta Materialia 59 (November) (2010) 830-840.

[27] S. Rosset, M. Niklaus, P. Dubois, H.R. Shea, Mechanical characterization of a dielectric elastomer microactuator with ion-implanted electrodes, Sensors and Actuators A 144 (2008) 185-193.

[28] B. Gaihre, G. Alici, G.M. Spinks, J.M. Cairney, Synthesis and performance evaluation of thin film PPy-PVDF multilayer actuator, Sensors and Actuators A: Physical 165 (February (2)) (2011) 321-328.

[29] S.W. John, G. Alici, C.D. Cook, Validation of a resonant frequency model for polypyrrole trilayer actuators, IEEE/ASME Transactions on Mechatronics 13 (August (4)) (2008) 401-409.

\section{Biographies}

Gursel Alici received the Ph.D degree in Robotics from the Department of Engineering Science, Oxford University, UK, in 1994. He is currently a Professor at the University of Wollongong, NSW, Australia, where he is the head of the School of Mechanical, Materials, and Mechatronic Engineering. His current research interests include intelligent mechatronic systems involving mechanisms/serial/parallel robot manipulators, micro/nano robotic systems for medical applications, and modeling, analysis, characterization, control of conducting polymers as macro/micro/nano sized-actuators and sensors for robotic and bio-inspired applications. He is a technical editor of IEEE/ASME Transactions on Mechatronics, a member of the Mechatronics National Panel formed by the Institution of Engineers, Australia. He is one of the chief investigators of the Australian Research Council Center of Excellence for Electromaterials Science in the Energy conversion and Bionics programs. Gursel Alici who has published more than 160 refereed publications in his areas of research is also the recipient of the Outstanding Contributions to Teaching and Learning (OCTAL) award from the University of Wollongong in 2010.

Andres Punning received the M.Sc. degree in physics and Ph.D. degree from Tartu University, Tartu, Estonia, in 1984 and 2007, respectively. His doctoral research concerned the modelling of the ionic polymer-metal composites. From 1984 to 2002, he was involved in the field of information technology and telecommunications. Since 2002, he has been a Researcher with the Institute of Technology Intelligent 
Materials and Systems Laboratory, Tartu University. Between 2009-2010, he was a postdoctoral researcher at Microsystems for Space Technologies Laboratory of the Ecole Polytechnique Fédérale de Lausanne, worked on miniature dielectric elastomer actuators with ion implanted electrodes. His current research interest is the development of ionic and dielectric polymer actuators and sensors.

Herbert R. Shea holds a Ph.D. (1997) in physics from Harvard University. After a postdoc in carbon nanotube electronics at IBM's T.J. Watson Research Center in Yorktown
Heights, NY, he joined Lucent Technologies' Bell Labs in Murray Hill, NJ, where he became the technical manager of the Microsystems Technology group, specializing in MEMS reliability. In 2004 he founded the Microsystems for Space Technologies Laboratory at the EPFL in Switzerland, where he is currently an associate professor. Current research topics include micromachined polymer actuators, electric micropropulsion, MEMS sensors for satellite attitude determination, chip-scale plasma sources, and picosatellites. 